\title{
Analysis and Implementation of Positive Output Super Lift Converter Using Artificial Neural Network with Sliding Mode Controller
}

\author{
Venkataramani VENKATESH*, Chokkalingam KAMALAKANNAN \\ Department of EEE, Rajalakshmi Engineering College, Tamilnadu, India \\ vvvsh1986@gmail.com (*Corresponding author), kamalakannan.c@rajalakshmi.edu.in
}

\begin{abstract}
This paper proposes the control of split capacitor type elementary additional series positive output super lift converter (SEPOSLC) by using artificial neural-network (ANN) with sliding mode controller. This converter implements the output voltage increase in geometric sequence and enhances the voltage transfer gain in power law. The ANN controller is trained to control the converter so that it produces constant output voltage irrespective of change in the input voltage. ANN with sliding mode control (SMC) is proposed for this converter with a view to controlling voltage ripple. The precision of the proposed system is analyzed in comparison with various controllers such as the ANN controller, Fuzzy logic controller, and conventional PI controller. In order to validate the effectiveness of the proposed system, it is implemented in hardware with linear and nonlinear loads.
\end{abstract}

Keywords: ANN, ANN with sliding mode controller, BLDC motor, FLC, PI, SEPOSLC.

\section{Introduction}

Nowadays DC-DC converters play a major role in the world of power electronics. Theoretically, the basic DC-DC converters like the boost, buckboost, Cuk, single-ended primary inductor converter (SEPIC), etc., can reach peak step-up voltage transfer gain with an enormous high duty cycle (Tran et al., 2018), (Lu, Cheng \& Lee, 2003). Unfortunately, in practice, the step-up voltage gain is bounded due to the outcome of power switches, rectifier diodes and the equivalent series resistance (ESR) of inductors and capacitors. Moreover, the extremely high Dutycycle process will tend to a major reverse retrieval problem (Nguyen et al., 2018).

Positive output super-lift converters (Luo \& Ye, 2003) are a series of attractive DC-DC topologies, which provides very high step-up voltage transfer gains due to cascade connection and the transformerless operation. Super-lift converters utilize the voltage lift (VL) technique, which is an effective method broadly used in electronic circuit design (Zhu \& Luo, 2009), for understanding the throughput improvement.

Super-lift (SL) technique implements the output voltage increase step by step in the geometric progression (El-Ghanam, 2020). It effectively enhances the voltage transfer gain in power series. There are two such subseries in super lift converters namely main series and additional series. The main series is categorized into the elementary circuit, relift circuit, and triple-lift circuit. Additional series are extracted from the corresponding circuits of the main series.
The PI controller design has been limited for many years (Alvarez-Ramirez et al., 2001), (Garcerá et al., 2004). The choice of the elements of control system is a tradeoff between robustiousness and quick transient outcome. The fuzzy control system is a mathematical control system capable of dealing with imprecise data and it is analyzed by various researchers for controlling DC-DC converter (Elmas et al., 2009), (Gupta et al., 1997), (Guo et al., 2011). An alternative sketch technique for recognizing and controlling these systems was presented by (Seshagiri \& Khalil 2000), (Shoja-Majidabad \& Hajizadeh 2020) (Hassan \& Kothapalli, 2012) by the neural-network-based control method.

Though DC-DC converters are typical variable structure systems, for controlling such system variable structure control namely sliding mode (SM) control (Goudarzia \& Khosravi, 2018), (Repecho et al., 2018), (Tan \& Lai, 2008) is the suitable one. Hence, in this study SMC is employed along with ANN controller for potential control in SEPOSLC.

The organization of this research article is as follows: Section 2 describes working of SEPOSLC converter. Modeling of transfer function of SEPOSLC Converter is presented in Section 3. Section 4 discusses PI controller based SEPOSLC Converter. Fuzzy logic controller for SEPOSLC is presented in section 5. Section 6 sets forth ANN controller-based converter. Section 7 puts forward ANN with SMC controller based SEPOSLC 
Converter. Section 8 addresses SEPOSLC with inverter fed brushless DC (BLDC) motor. Section 9 presents the results attained from the simulation analysis. Section 10 sets forth the detailed result of experimental analysis and finally Section 11 presents the conclusion of this article.

\section{Working of SEPOSLC Converter}

The schematic illustration of SEPOSLC converter contains both the active and passive components represented in the Figure 1(a). The active voltage supply for SEPOSLC converter is a DC power source $V_{i n}$. Resistor $R_{0}$ is a load, capacitors $C_{1}, C_{2}, C_{3}, C_{4}, C_{5}$, and inductor $L_{1}$ are the passive parameters of SEPOSLC converter. N-channel metal-oxide-semiconductor field-effect transistor (MOSFET) switch and freewheeling diodes are the power switching components contained in the SEPOSLC circuit for moving the current in the DC bias.

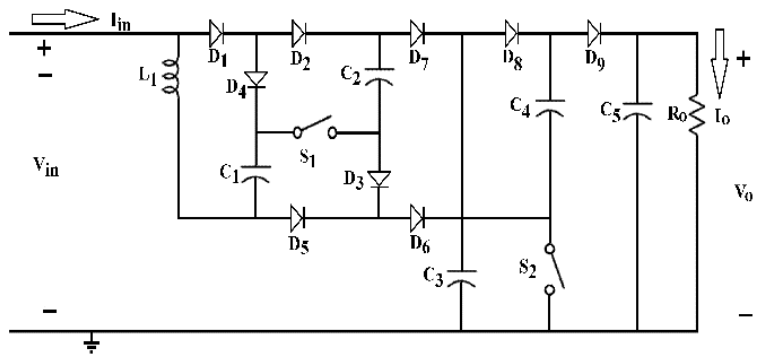

(a)

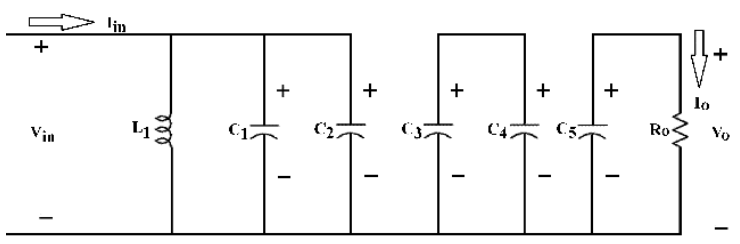

(b)

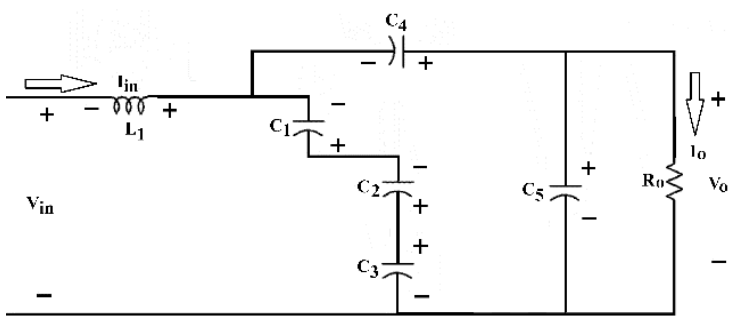

(c)

Figure 1. (a). Schematic layout of split capacitor type elementary additional series positive output super lift converter, (b) Schematic layout for mode 1 (ON state) of SEPOSLC converter, (c) Schematic diagram for mode 2 (OFF state) of SEPOSLC converter

There are two n-channel MOSFETs $\mathrm{S}_{1}$ and $\mathrm{S}_{2}$ implemented in the SEPOSLC converter. In the converter schematic the resistor $\mathrm{R}_{0}$ is assumed as load resistance. $D_{1}, D_{2}, D_{3}, D_{4}, D_{5}, D_{6}, D_{7}, D_{8}, D_{9}$ are the nine diodes present in the schematic diagram. On the time of switching condition, forwarding of current is precisely done by using diodes in the converter schematic diagram.

It is assumed that the split capacitor type elementary additional series positive output super lift converter works in ideal state and continuous conduction mode. There are two switching modes that the converter schematic will undergo (Leyva et al., 1997). When the switch $S_{1}$ is closed and $S_{2}$ is open SEPOSLC converter achieves mode 1. When the switch $\mathrm{S}_{1}$ is open and $\mathrm{S}_{2}$ is closed SEPOSLC converter attains mode 2 . The schematic layout of SEPOSLC converter is represented for both modes. For both mode 1 (ON state) and mode 2 (OFF state) the state space illustration of the SEPOSLC schematic is designed.

By adding up the ON system matrix with (1-k) the OFF system matrix, the system matrix illustration of the whole split capacitor type elementary additional series positive output super lift converter schematic is acquired. The SEPOSLC state matrix using state space to transfer function conversion formula in MATLAB software for the transfer function is acquired. The stability of the acquired transfer function is described by Bode plot and root locus. The conversion of state space to transfer function through the common coding is stated below.

$[\mathrm{b}, \mathrm{a}]=\operatorname{sstof}(\mathrm{A}, \mathrm{B}, \mathrm{C}, \mathrm{D})$

\section{Report on MODE 1 (ON State)}

The schematic layout of SEPOSLC converter in mode 1 (ON state) is shown in the Figure 1(b). When the input voltage $V_{\text {in }}$ is applied to the capacitors $\mathrm{C}_{1}$ and $\mathrm{C}_{2}$, capacitors get charged to achieve the steady state condition. When $V_{\text {in }}$ is given in this mode, the flow of current via the inductor $\mathrm{L}_{1}$ will rise. The switching time for mode 1 (ON state) is $k T$ (Venkatesh \& Kamalakannan, 2016).

Using the electrical circuit analysis, the state space illustration for mode 1 of split capacitor type elementary additional series positive output super lift converter is acquired. A $6 \times 6$ matrix is developed for the system matrix for the mode 1 , because the schematic diagram includes six passive components. The state matrix (A), input matrix (B), output matrix (C) and feedthrough matrix (D) make up the system matrix. The state space representation in the Standard formula is stated below. 


$$
\begin{aligned}
& \frac{d x(t)}{d t}=A x(t)+B u(t) \\
& y(t)=C x(t)+D u(t)
\end{aligned}
$$

Equations (4) and (5) express the system matrix for mode 1 SEPOSLC schematic

$$
\frac{d}{d t}\left(\begin{array}{c}
i_{L 1} \\
V_{c 1} \\
V_{c 2} \\
V_{c 3} \\
V_{c 4} \\
V_{c 5}
\end{array}\right)=
$$$$
=\left(\begin{array}{cccccc}
0 & -\frac{1}{L_{1}} & 0 & 0 & 0 & 0 \\
-\frac{1}{C_{1}} & 0 & -\frac{C_{2}}{C_{1}} & 0 & 0 & 0 \\
-\frac{1}{C_{2}} & -\frac{C_{1}}{C_{2}} & 0 & -\frac{C_{3}}{C_{2}} & 0 & 0 \\
\frac{1}{C_{3}} & \frac{C_{1}}{C_{3}} & \frac{C_{2}}{C_{3}} & 0 & -\frac{C_{4}}{C_{3}} & 0 \\
\frac{1}{C_{4}} & \frac{C_{1}}{C_{4}} & \frac{C_{2}}{C_{4}} & \frac{C_{3}}{C_{4}} & 0 & \frac{C_{5}}{C_{4}} \\
\frac{1}{C_{5}} & \frac{C_{1}}{C_{5}} & \frac{C_{2}}{C_{5}} & \frac{C_{3}}{C_{5}} & \frac{C_{4}}{C_{5}} & 0
\end{array}\right)\left(\begin{array}{l}
V_{L 3} \\
V_{1} \\
V_{2} \\
V_{3} \\
V_{5}
\end{array}\right)+
$$

$$
+\left(\begin{array}{c}
\frac{1}{L_{1}} \\
\frac{1}{R_{\text {in }} C_{1}} \\
\frac{1}{R_{\text {in }} C_{2}} \\
0 \\
0 \\
0
\end{array}\right) V_{\text {in }}
$$

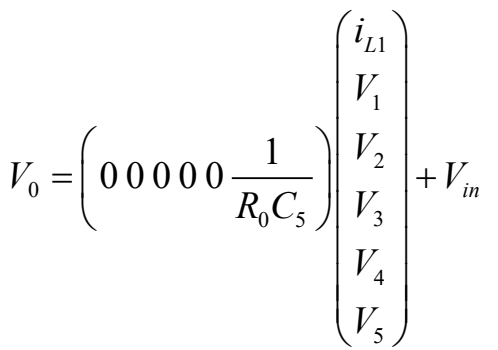

\section{Report on MODE 2 (OFF State)}

The schematic diagram for SEPOSLC converter under mode 2 condition is shown in Figure 1(c). When the input voltage $V_{\text {in }}$ is applied to the capacitors $\mathrm{C}_{1}$ and $\mathrm{C}_{4}$, capacitors get charged to achieve the steady state condition. When $V_{i n}$ is given in this mode, the flow of current via the inductor $\mathrm{L}_{1}$ decreases. The switching time of mode 2 (OFF state) is (1-kT).
Using the electrical circuit analysis, the state space illustration for the mode 2 of split capacitor type elementary additional series positive output super lift converter is acquired. A $6 \times 6$ matrix is formed for the system matrix for mode 2 , because of the six passive components inside the circuit. The state matrix (A), input matrix (B), output matrix (C) and feedthrough matrix (D) make up the system matrix. The system matrix is represented in the General formula which is stated below.

In equations (6) and (7) the state space representation for the mode 2 SEPOSLC circuit is shown.

$\frac{d}{d t}\left(\begin{array}{l}i_{L 1} \\ V_{c 1} \\ V_{c 2} \\ V_{c 3} \\ V_{c 4} \\ V_{c 5}\end{array}\right)=$

$=\left(\begin{array}{cccccc}0 & \frac{-1}{L_{1}} & 0 & 0 & 0 & 0 \\ \frac{1}{C_{1}} & 0 & 0 & 0 & -\frac{C_{4}}{C_{1}} & 0 \\ \frac{1}{C_{2}} & \frac{C_{1}}{C_{2}} & 0 & -\frac{C_{3}}{C_{2}} & 0 & 0 \\ \frac{1}{C_{3}} & \frac{C_{1}}{C_{3}} & \frac{C_{2}}{C_{3}} & 0 & -\frac{C_{4}}{C_{3}} & 0 \\ \frac{1}{C_{4}} & \frac{C_{1}}{C_{4}} & \frac{C_{2}}{C_{4}} & \frac{C_{3}}{C_{4}} & 0 & -\frac{C_{5}}{C_{4}} \\ \frac{1}{C_{5}} & \frac{C_{1}}{C_{5}} & \frac{C_{2}}{C_{5}} & \frac{C_{3}}{C_{5}} & \frac{C_{4}}{C_{5}} & 0\end{array}\right)\left(\begin{array}{l}i_{L 3} \\ V_{1} \\ V_{2} \\ V_{3} \\ V_{4} \\ V_{5}\end{array}\right)+$

$$
+\left(\begin{array}{c}
\frac{1}{L_{1}} \\
\frac{1}{R_{i n} C_{1}} \\
\frac{1}{R_{i n} C_{2}} \\
\frac{1}{R_{i n} C_{3}} \\
\frac{1}{R_{i n} C_{4}} \\
0
\end{array}\right) V_{\text {in }}
$$

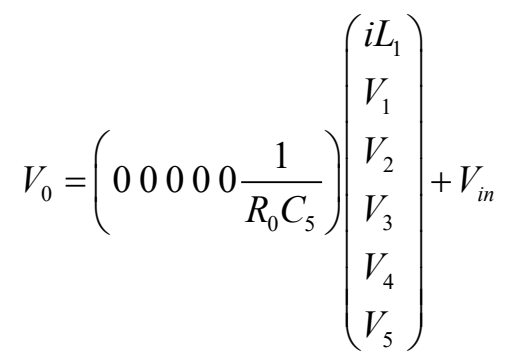




\section{Modeling of Transfer Function of SEPOSLC Converter}

Equations (8), (9), (10) show the entire state space representation of the split capacitor type elementary additional series positive output super lift converter

$\mathrm{T}(\mathrm{S})=\mathrm{ON}$ state matrix $+(1-\mathrm{k})$ OFF state matrix

Expression (9) is attained by substituting ON state and times OFF state matrix in equation (8). The complete SEPOSLC schematic state matrix and the output matrix is the sum of ON state matrix with (1-k) times OFF state matrix. The resistor value is $50 \Omega$, each capacitor value $\left(C_{1}, C_{2}, C_{3}, C_{4}, C_{5}\right)$ is $30 \mu \mathrm{F}$ and inductor $L_{1}$ of $100 \mu \mathrm{H}$ are considered for acquiring the transfer function of the split capacitor type elementary additional series positive output super lift converter.
$C_{1}-C_{5}$. The acquired transfer function is expressed as follows (12).

$L=\frac{V_{\text {in }} \cdot k \cdot T}{\Delta I_{L}}$

The obtained transfer function is given below equation (13).

Let $M=$ Top Row, $N=$ Bottom Row, then $T(s)=$ $M / N$

$M=3.704 * 10^{11} s^{2}+1.235 * 10^{22} s+2.877 * 10^{11}$, $N=s^{6}+1.693 * 10^{9} s^{5}+5.789 * 10^{10} s^{4}+2.483 *$

$* 10^{15} s^{3}+8.029 * 10^{19} s^{2}+1.235 * 10^{22} s$, then

$T(s)=M / N$

It can be noticed that, on the time of switch OFF state the inductor current decreases and on the time

$\frac{d}{d t}\left(\begin{array}{l}i_{L 1} \\ V_{c 1} \\ V_{c 2} \\ V_{c 3} \\ V_{c 4} \\ V_{c 5}\end{array}\right)=\left(\begin{array}{cccccc}0 & \frac{k-2}{L_{1}} & 0 & 0 & 0 & 0 \\ \frac{-k}{C_{1}} & 0 & \frac{-C_{2}}{C_{1}} & 0 & -\frac{C_{4}(1-k)}{C_{1}} & 0 \\ \frac{-k}{C_{2}} & \frac{-k C_{1}}{C_{2}} & 0 & \frac{C_{3}(k-2)}{C_{2}} & 0 & 0 \\ \frac{2-k}{C_{3}} & \frac{C_{1}(2-k)}{C_{3}} & \frac{C_{2}(2-k)}{C_{3}} & 0 & \frac{-k C_{4}}{C_{3}} & 0 \\ \frac{2-k}{C_{4}} & \frac{C_{1}(2-k)}{C_{4}} & \frac{C_{2}(2-k)}{C_{4}} & \frac{C_{3}(2-k)}{C_{4}} & 0 & \frac{k C_{4}}{C_{5}} \\ \frac{2-k}{C_{5}} & \frac{C_{1}(2-k)}{C_{5}} & \frac{C_{2}(2-k)}{C_{5}} & \frac{C_{3}(2-k)}{C_{5}} & \frac{C_{4}(2-k)}{C_{5}} & 0\end{array}\right)\left(\begin{array}{l}i_{L 1} \\ V_{1} \\ V_{2} \\ V_{3} \\ V_{4} \\ V_{5}\end{array}\right)+\left(\begin{array}{c}\frac{2-k}{L_{1}} \\ \frac{2-k}{R_{i n} C_{1}} \\ \frac{2-k}{R_{i n} C_{2}} \\ \frac{1-k}{R_{i n} C_{1}} \\ \frac{1-k}{R_{i n} C_{4}} \\ \frac{1-k}{R_{i n} C_{4}}\end{array}\right) V_{i n}$

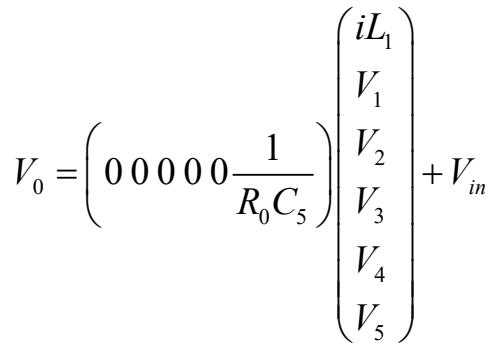

The values of inductor $L_{1}$ and capacitor $C_{1}-C_{5}$ are given below

$C_{i}=\frac{(1-k) V_{O}}{f * \Delta V_{O} * R_{0}} \quad i=1,2 . ., 5$

where $f$ is switching frequency, $\Delta V_{O}$ is the voltage ripple. Equation (11) is employed for all capacitors of switch ON state inductor current increases; the upcoming equations show the peak-to-peak inductor ripple current $\left(\Delta_{i L}\right)$ and voltage transfer gain.

$$
\begin{aligned}
& \Delta_{i L}=\frac{V_{i n}}{L} k T=\frac{V_{o}-V_{1}-V_{i n}}{L}(1-k) T \\
& V_{0}=\left(\frac{1}{1-k}+\frac{3-2 k}{1-k}\right) V_{i n}
\end{aligned}
$$

Where $V_{1}$ is voltage across capacitor. The voltage transfer gain $(G)$ is:

$G=\frac{V_{0}}{V_{\text {in }}}=\left(\frac{4-2 k}{1-k}\right)$ 


\section{PI Controller based Converter}

The traditional Proportional Integral controller is a simple method and is extensively utilized in various applications. PI controller raises the reaction speed. It creates minute level of steady state error. In this study voltage error is given as input to PI control system and response is accepted as the duty ratio of the switch in the converter.

General equation of PI controller is given below

$$
U(s)=K_{p} E(s)+\frac{K_{i}}{s} E(s)
$$

where proportional constant is $\mathrm{K}_{\mathrm{p}}$, the integral gain is $\mathrm{K}_{\mathrm{i}}$, controller input and the controller output is given as $\mathrm{E}(\mathrm{s})$ and $\mathrm{U}(\mathrm{s})$. The optimal values of $\mathrm{K}_{\mathrm{p}}$ \& $\mathrm{K}_{\mathrm{i}}$ are found by using Ziegler-Nichols' technique. But this control system produces high overshoot and voltage ripple.

\section{Converter Control Using Fuzzy Logic Controller}

The numerical method for handling the inexact data and bugs that have numerous keys instead of one is the Fuzzy logic controller (FLC). In FLC non integer, Linguistic, variables are utilized, making it similar to the way humans think. Fuzzy control method is an efficient way for handling the instabilities and unpredictability relating to vagueness (Leyva et al., 1997). In this study, FLC is employed to control overshoot.

Fuzzy inference system is the full title for the scheme which utilizes fuzzy reasoning for mapping an input space into an output space. Numerous methods describe the outcome of this procedure; this study implements the maxmin technique of inference. Voltage error $(e)$ and change in error (ec) are the two inputs of Mamdani-type fuzzy controller. FLC produces duty ratio as output.

$e_{v}=V^{*}-V_{o}$

In (18) $V^{*}$ is the reference voltage. NB negative big, NS - negative small, $\mathrm{Z}$ - zero, PS -positive small and PB - positive big are the five membership functions of output and both inputs. The analytical method for converting fuzzy values into crisp values is stated as defuzzification. Among various types of defuzzification methods, centroid method of defuzzification is used in this study. Fuzzy rules of D are illustrated in Table 1. Figure 2(a) shows the input membership functions, Figure 2(b) shows the Output membership functions of D (Ofoli \& Rubaai, 2006).

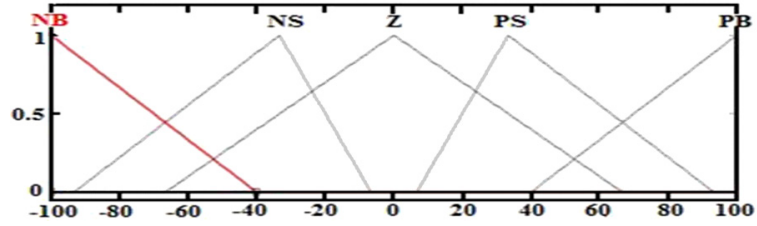

(a)

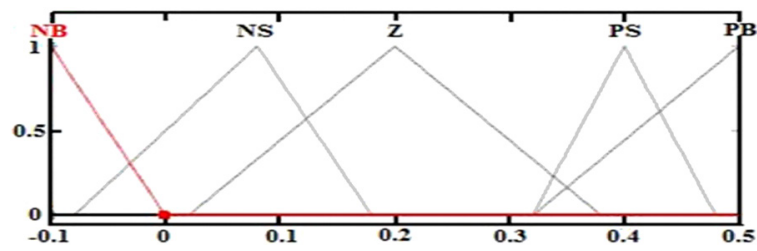

(b)

Figure 2. (a). Membership functions of input e \& ec, (b) Output Membership functions of D

Table 1.Fuzzy Rules of D

\begin{tabular}{|c|c|c|c|c|c|}
\hline ec & NB & NS & $Z$ & PS & PB \\
\hline NB & NB & NS & NS & Z & PS \\
\hline NS & NB & NS & NS & PS & PB \\
\hline$Z$ & NB & NS & Z & PS & PB \\
\hline PS & NB & NS & PS & PS & PB \\
\hline PB & NS & Z & PS & PS & PB \\
\hline
\end{tabular}

\section{Report of Artificial Neural Network}

Artificial Neural Networks are computational models, their process is based on parallel processing. Weights are one of the internal parameters of the processing parameters. Any dynamic, linear or nonlinear, actions of transmission in the network can be practically performed by varying the weights (Ofoli \& Rubaai, 2006).

By assuming these characteristics, the neural networks can also be used as a control system for switch-mode systems. The back-propagation algorithm, delta learning rule, Hoffman adaptive neural scheme, wizhai training technique and selforganizing map were used for the intended DC 
to DC converter for implementing the Artificial Neural Network Controller.

\section{Edifying the Neurons}

The linear structure is implemented in ANN control system. The ANN controller does the following steps (Beale et al., 2010):

- The scalar input ' $p$ ' is multiplied with the weight. Thus, for every feedback cycle, the input will increase;

- The delay unit holds up the computed data for a specified period of time. By the multiplexer, the data hold-up is created in the delay unit, then the processed input is multiplexed again;

- The holdup input is added with the scalar bias. The output of the dot product unit is also multiplexed;

- The total network addition of the response (z) is fed to the saturation unit, for checking if the linearized output attains the saturation condition;

- The scalar variable ' $p$ ' is once again computed with the acquired output. So that the output is precise corrected and gets increased for every feedback cycle. Thus, the ANN controller produces the output;

- TheANN control system response is relationally compared with the reputational series pulses;

- The gate signal for $\mathrm{S}_{2}$. is provided based on the compared response. The gate signal for $\mathrm{S}_{1}$ is given based on compared response and based on inverted response (z).

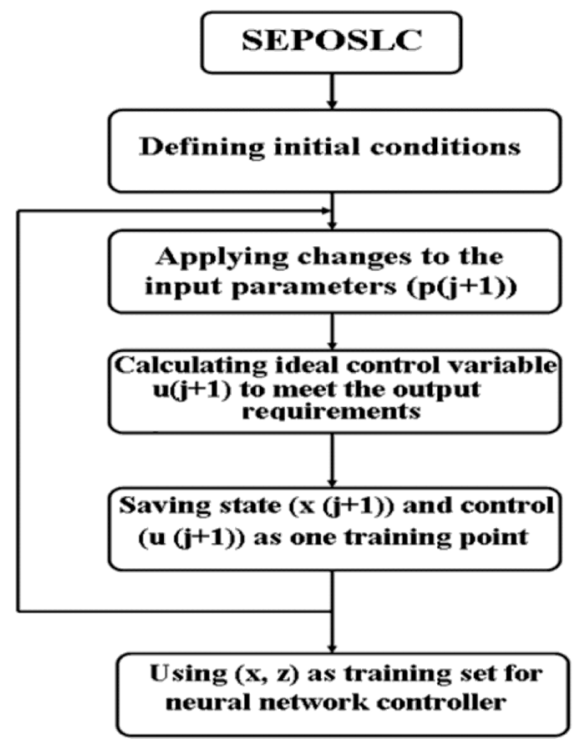

Figure 3. Flow chart of artificial neural network controller
The inputs provided for ANN controller are exact response voltage acquired by the SEPOSLC and rate-limited reference voltage. By multiplexing the two inputs, the ANN controller gets the selected input. Flow diagram of ANN controller is shown in Figure 3.

\section{ANN with SMC for Converter Control}

In order to control the duty ratio of the converter the sliding surface is attained. In a conventional sliding mode controller, the voltage error is $X_{1}, X_{2}$ is the amount of change in voltage error, $X_{3}$ is the addition of voltage error. The switching function adopted General SM control law as follows

$\mathrm{U}=1$ when $\mathrm{S}>0$

$\mathrm{U}=0$ when $\mathrm{S}<0$

$U=\frac{1}{2(1+\operatorname{sgn}(S))}$

$\mathrm{S}$ is the instant state variable's path which is depicted below

$\mathrm{S}=\mathrm{m}_{1} X_{1}+\mathrm{m}_{2} X_{2}+\mathrm{m}_{3} X_{3}$

where $\mathrm{m}_{1}, \mathrm{~m}_{2}$ and $\mathrm{m}_{3}$ are sliding coefficients. By enforcing $\mathrm{S}$ to 0 sliding surface is attained. To minimize these computations in this paper simplified SMC is analyzed. The duty ratio tuned by the ANN is applied to this controller, and the sliding surface enforces converter to produce the required voltage.

$S_{v}=e_{v}+K_{v} \int e_{v} d t$

In equation (21) $\mathrm{e}_{v}$ is the voltage error and $\mathrm{K}_{\mathrm{v}}$ is the controller design constant.

Since the output of ANN is again fine-tuned using SMC, the ANN-SMC controller attains improved performance compared to all other controllers.

\section{SEPOSLC with Inverter Fed BLDC Motor}

For analyzing the nonlinear load in an SEPOSLC converter, three-phase inverter fed BLDC motor is proposed. Three-phase insulated-gate bipolar transistor (IGBT) inverter is supplied from the converter, and it is controlled by using Hall Effect sensor, decoder signal from BLDC motor. The 
controlled voltage from the converter enhances the performance of motor and reduces the steadystate error.

\section{Simulation Results of SEPOSLC Converter}

Matlab/Simulink model is developed to analyze various controllers based SEPOSLC Converter powered three-phase BLDC motor. The simulation model is developed with an adjustable voltage supply. The response voltage is feedback to voltage controller. The response of control system is compared with a saw-like carrier wave and produced signals are fed to the switches in the converter.

\section{Input Variance in SEPOSLC Converter}

The input voltage varies from $6 \mathrm{~V}-12 \mathrm{~V}$ to analyze the performance of various controllers proposed. The response voltage from the systematic outcome of SEPOSLC converter for input of $14 \mathrm{~V}$ using PI, FLC, ANN, ANN with SMC is shown in Figure 4.

From Figure 4(a), it can be noticed that PI controller in converter control produces a voltage which is close to the reference value. But it produces high overshoot as well as ripple in voltage in the response voltage. Overshoot at the output is referred as overvoltage to load produced due to the poor control of converter. Voltage ripple makes the voltage to the load oscillate which reduces performance and life of load.

From Figure 4(b), it is obvious that fuzzy controller in converter control eliminates overshoot. Elimination of overshoot avoids excess voltage to the load, but voltage ripple produced by FLC controlled converter is yet to be reduced.

From Figure 4(c), one can notice effectiveness of artificial intelligent ANN controller in converter control. ANN eliminates overshoot and reduces voltage ripple effectively compared to PI and FLC. But the range of voltage ripple is $1.2 \%$ which is very low compared to the $2.1 \%$ and $4.4 \%$ of ripple produced by PI and FLC respectively. Even though the voltage ripple is low, this will lead to ripple in the inverter voltage and results in oscillation in the speed of BLDC motor.

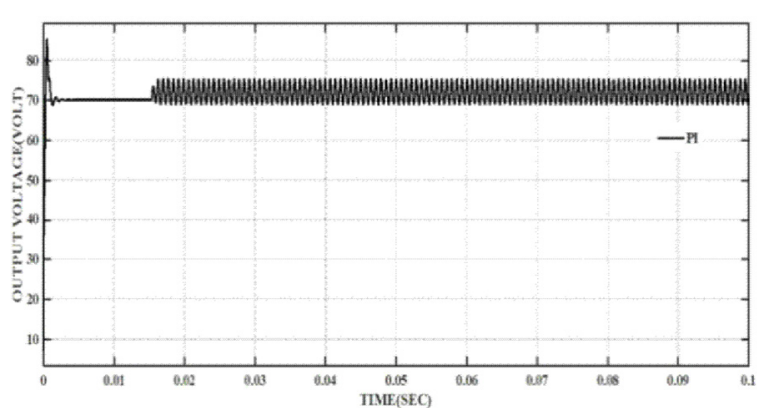

(a)

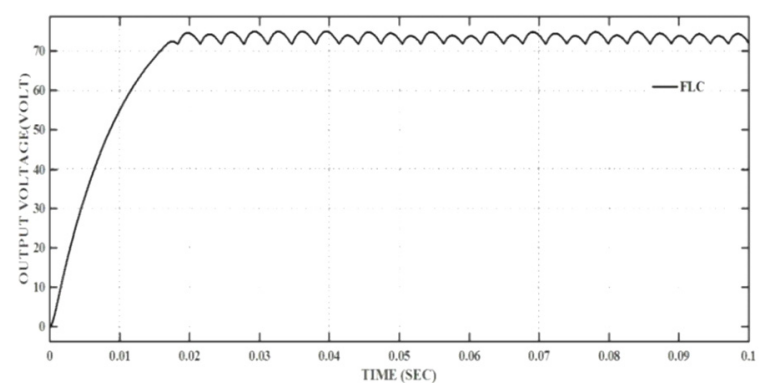

(b)

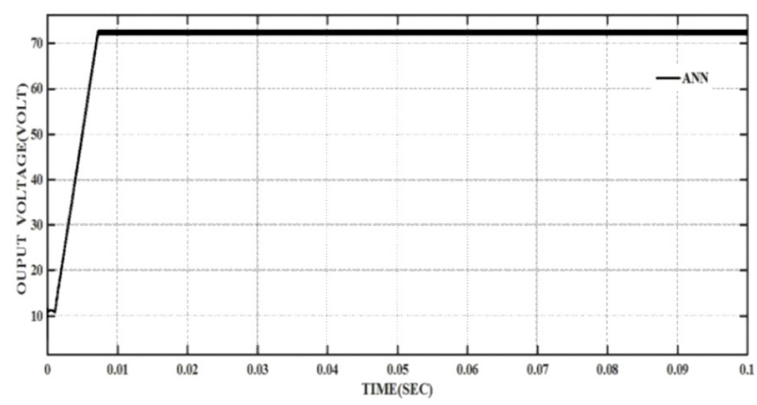

(c)

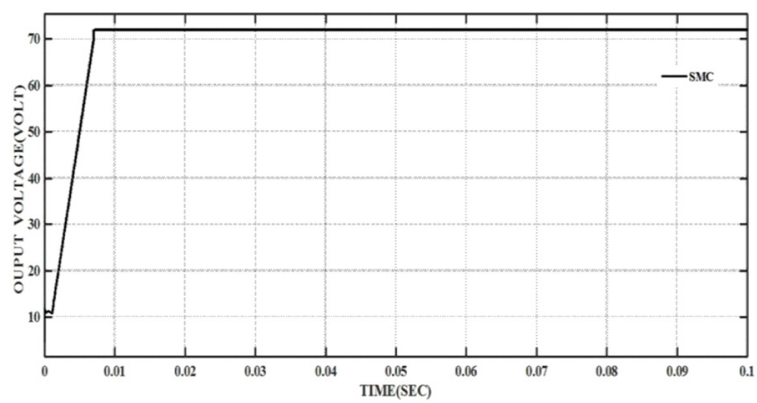

(d)

Figure 4. Performance of SEPOSLC converter at 14V input, (a) Performance of PI, (b) Performance of FLC, (c) Performance of ANN, (d) Performance of

\section{ANN-SMC}

From Figure 4(d), one can notice that proposed ANN with SMC controller eliminates overshoot and reduces the voltage ripple to $0.029 \%$. In comparison with the conventional PI controller almost $99 \%$ of voltage ripple is reduced by the 
proposed ANN with SMC controller. It results in the elimination of overvoltage and oscillation in the speed of motor connected with the converterfed drive. This is the required property of the converter for running the inverter-fed motor.

From Table 2, it can be noticed that only PI produces overshoot in voltage. FLC eliminates overshoot, but voltage ripple is high. ANN controller also eliminates overshoot, and it minimizes the voltage ripple. ANN SMC control system provides higher throughput in comparison with all other control systems with regard to peak overshoot, voltage ripple and settling time. Hence ANN SMC controller which attains best performance is executed in hardware for experimental analysis.

Table 2. Trade-off of various controllers on SEPOSLC converter

\begin{tabular}{|c|c|c|c|}
\hline Controllers & $\begin{array}{c}\text { Peak } \\
\text { overshoot } \\
(\mathbf{\%})\end{array}$ & $\begin{array}{c}\text { Voltage } \\
\text { ripple (\%) }\end{array}$ & $\begin{array}{c}\text { Settling } \\
\text { time (sec) }\end{array}$ \\
\hline PI & 18.35 & 2.1 & 0.004 \\
\hline FLC & 0 & 4.4 & 0.0183 \\
\hline ANN & 0 & 1.223 & 0.0072 \\
\hline ANN-SMC & 0 & 0.02916 & 0.006996 \\
\hline
\end{tabular}

\section{Hardware Output of SEPOSLC Converter}

\section{Experimental Setup of the Intended System}

The converter is designed to produce $12 \mathrm{~V}$ output with various loads. Table 3 includes the hardware requirements for the intended system.

Table 3. Hardware specifications

\begin{tabular}{|c|c|c|}
\hline $\begin{array}{c}\text { S. } \\
\text { No }\end{array}$ & Requirements & Device or Software \\
\hline 1 & Embedded Controller & PIC16F887 \\
\hline 2 & Coding & $\begin{array}{c}\text { Embedded C } \\
\text { Language }\end{array}$ \\
\hline 3 & C compiler & HITECH C \\
\hline 4 & Simulator & MPLAB Simulator \\
\hline 5 & Programmer & PIC KIT3 Programmer \\
\hline 6 & $\begin{array}{c}\text { Schematic Software } \\
\text { (Circuit Designing) }\end{array}$ & Express Schematic \\
\hline 7 & $\begin{array}{c}\text { Printed Circuit Board } \\
\text { (PCB) Designing }\end{array}$ & Express PCB \\
\hline
\end{tabular}

https://www.sic.ici.ro

\section{Experimental Setup for the Proposed System with Resistive Load}

For a linear load analysis ANN with SMCcontrolled SEPOSLC converter is analyzed with resistive load of $50 \Omega$. Figure 5 shows the experimental setup of SMC-controlled SEPOSLC with resistive load.

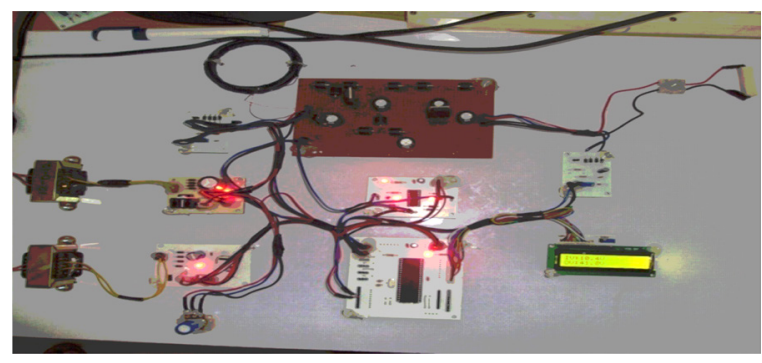

Figure 5. Experimental setup of Intended System with resistive load

For an analysis of ANN with SMC variable input voltage $6 \mathrm{~V}$ to $11 \mathrm{~V}$ is given to the SEPOSLC to produce $12 \mathrm{~V}$ output. The input and response voltage of intended system along with resistive load are shown in Figure 6.

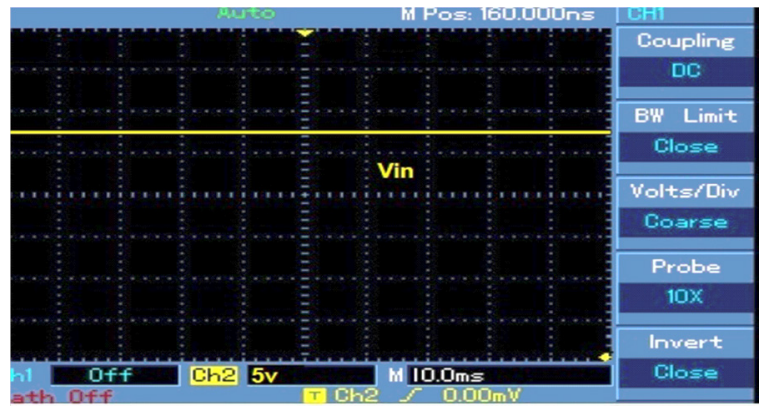

(a)

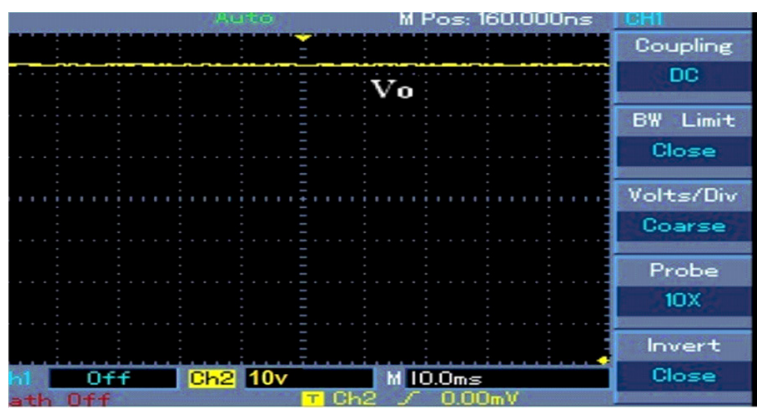

(b)

Figure 6. Performance of SEPOSLC converter using ANN with SMC for 8V input with resistive load (a) Input voltage of SEPOSLC at 8V (b) Output voltage of SEPOSLC at $8 \mathrm{~V}$ input

In Figure 6 it can be noticed that the input to the converter is increased to $12 \mathrm{~V}$ in SEPOSLC converter. The smooth response voltage of converter shows the effectiveness of ANN with SMC. 


\section{Experimental Setup for the Proposed System with BLDC Motor Load}

For an analysis of proposed system with the nonlinear load, SEPOSLC is proposed with the load of three-phase inverter-fed BLDC motor. $12 \mathrm{~V}, 3$-phase BLDC motor is considered as load. Figure 7 shows the hardware of SEPOSLC converter using ANN with SMC control system with BLDC motor load.

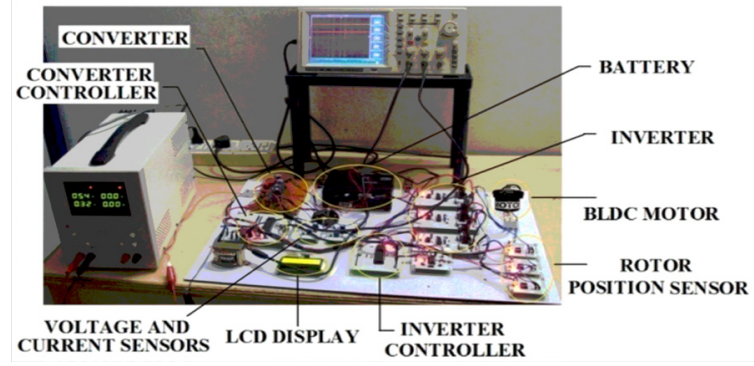

Figure 7. Hardware system with BLDC motor load

In comparison with hardware setup from Figure 5, in Figure 7, resistive load is replaced by a BLDC motor. Three-phase inverter circuit is introduced after a converter to feed AC supply to the motor. For an analysis ANN with SMC controller input voltage is varied for SEPOSLC converter.

Figure 8(a) shows the outcome of SEPOSLC converter using ANN with SMC for $8 \mathrm{~V}$ input. The orange color wave represents the input voltage while the yellow wave is the output voltage. For $8 \mathrm{~V}$ input, it produces $12 \mathrm{~V}$ output. Figure $8(\mathrm{~b})$ shows the pulse produced by the ANN-SMC controlled duty ratio for SEPOSLC converter. Figure 8(a) shows the effect of this control in output voltage control. The response of SEPOSLC converter using ANN with SMC for $11 \mathrm{~V}$ input is shown in Figure 8(c). For $11 \mathrm{~V}$ input, it produces $12 \mathrm{~V}$ output.

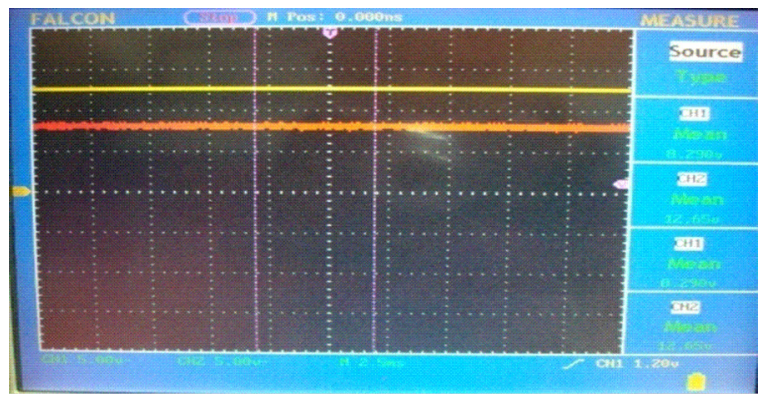

(a)

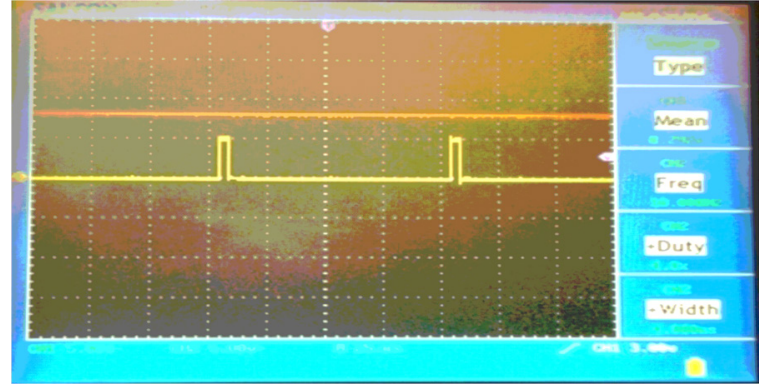

(b)

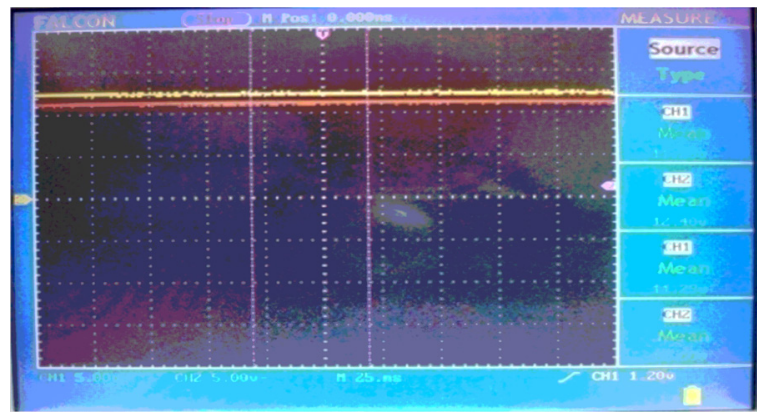

(c)

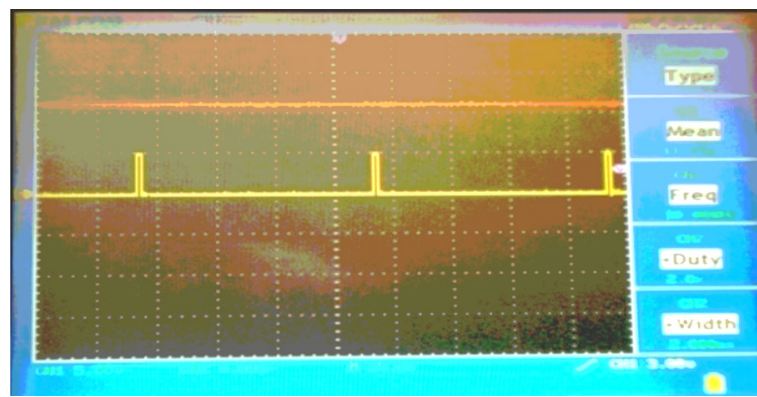

(d)

Figure 8. (a) Response of ANN-SMC controlled converter at $8 \mathrm{~V}$ input, (b) Duty ratio controlled by ANN SMC controller at $8 \mathrm{~V}$ input, (c) Response of ANN -controlled converter at $11 \mathrm{~V}$ input, (d) Duty ratio controlled by ANN SLC converter at $11 \mathrm{~V}$ input

Figure 8(d) shows the pulse width modulated (PWM) output produced by the ANN-SMC controller for SEPOSLC converter at the $11 \mathrm{~V}$ input. Figure 8(c) shows the effect of this control in response voltage control. It is obvious that the pulse width in Figure 8(d), is lower than in Figure $8(\mathrm{~b})$. In the case of Figure 8(b) input voltage is $8 \mathrm{~V}$, so the pulse width is large compared to pulse width in Figure 8(d) at $11 \mathrm{~V}$ input voltage.

From Figures 8(a) and (c) one can notice the performance of ANN controlled converter at $8 \mathrm{v}$ and $11 \mathrm{~V}$ inputs respectively, the converter gives constant $12 \mathrm{~V}$ output if the input is either $8 \mathrm{~V}$ or $12 \mathrm{~V}$. 
Figures $8($ b) and (d) show the pulse produced by ANN-SMC controlled duty ratio for the input of $8 \mathrm{v}$ and $11 \mathrm{~V}$ respectively. ANN-SMC controlled SEPOSLC varies pulse width or duty ratio based on the input voltage. Hence a change in duty ratio with respect to change in input voltage results in constant output voltage as it is shown in Figures 8(a) and (c). This controlled voltage is fed to three- phase inverter for supplying BLDC motor. Speed status of BLDC motor using ANN-SMC controlled SEPOSLC is shown in Figure 9.

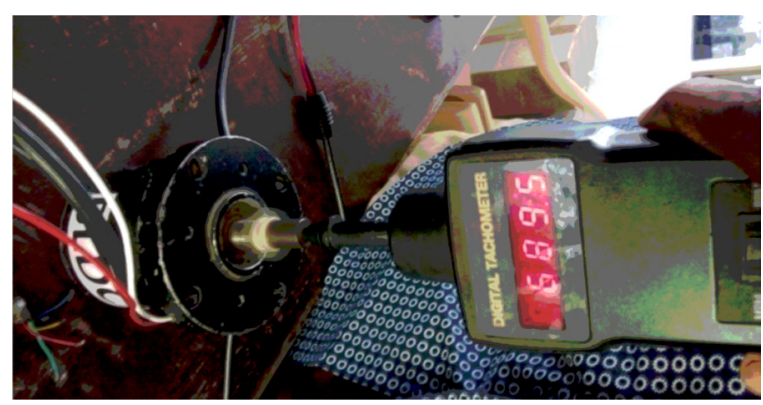

Figure 9. Speed status of BLDC motor using ANN-SMC controlled SEPOSLC

\section{Effectiveness of the System in Hardware}

The formula for calculating the effectiveness of the previously illustrated positive output super lift converter is

Efficiency $\eta=\frac{\text { output power }}{\text { input power }} * 100 \%$

Efficiency $\eta=\frac{\text { input power }(\mathrm{PE})-\operatorname{losses}(\mathrm{EL})}{\text { input power }(\mathrm{PE})} * 100 \%$

Efficiency $=70.81 \%$

The acquired effectiveness is low, and the remaining $29.19 \%$ of effectiveness is due to the usage of numerous passive components like one inductor, five capacitor, two MOSFET switches and nine diodes. The overall power loss due to these passive elements is calculated by using the formula below.

Total power loss

$=\mathrm{W}_{\mathrm{L} 1}+\mathrm{W}_{\mathrm{c} 1}+\mathrm{W}_{\mathrm{c} 2}+\mathrm{W}_{\mathrm{c} 3}$

$+\mathrm{W}_{\mathrm{c} 4}+\mathrm{W}_{\mathrm{c} 5}+\mathrm{W}_{\mathrm{sw} 1}+\mathrm{W}_{\mathrm{sw} 2}$

$+\mathrm{W}_{\mathrm{D} 1 \text { to } \mathrm{D} 9}$

Total power loss $=29.19 \mathrm{~W}$

\section{Technical Specification}

Table 4 illustrates the essential parameters and their corresponding values for the SEPOSLC converter.

Table 4. Parameter list of SEPOSLC converter

\begin{tabular}{|c|c|c|}
\hline Parameter list & Symbol & Value \\
\hline Input Voltage & $\mathrm{V}_{\text {in }}$ & $6 \mathrm{~V}$ \\
\hline Output Voltage & $\mathrm{V}_{\mathrm{o}}$ & $12 \mathrm{~V}$ \\
\hline Inductor & $L_{1}$ & $100 \mu \mathrm{F}$ \\
\hline Capacitor & $C_{1}-C_{5}$ & $30 \mu \mathrm{F}$ \\
\hline Nominal Switching Frequency & $f_{s}$ & $100 \mathrm{kHz}$ \\
\hline Load Resistance & $R_{0}$ & $50 \Omega$ \\
\hline Range of Duty Cycle & $k$ & 0.3 to 0.9 \\
\hline Desired Duty Cycle & $k$ & 0.5 \\
\hline
\end{tabular}

\section{Conclusion}

In this paper, SEPOSLC converter is analyzed in Matlab simulation by using different control systems such as PI, fuzzy logic controller and ANN controller. The throughput of all controllers is compared with the proposed ANN-SMC controller. ANN-SMC controller is proposed in this analysis with a view of reducing voltage ripple and peak overshoot in response voltage. In the framework of this systematic analysis, FLC in converter control system diminishes overshoot but increases the voltage ripple as compared to PI controller, whereas ANN-controlled converter produces no overshoot but generates voltage ripple in the range of $1.2 \%$ which has to be reduced. Proposed ANN with SMC controller attains satisfactory performance in all aspects compared to all other analyzed controllers.

Experimental analysis of proposed system with resistive load and BLDC motor load shows its effectiveness for a proposed system with linear and nonlinear load. The output voltage of converter is smooth and constant in both cases of loads such as resistive load and threephase inverter-fed BLDC motor load. From the experimental analysis it can be noticed that the throughput results of the proposed ANN-SMC controlled converter are similar to simulation results. The usage of ANN-SMC control system could be a better choice in a situation that requires exceptional regulation characteristics and excellent dynamical output specifications. 


\section{REFERENCES}

Alvarez-Ramirez, J., Cervantes, I., Espinosa-Perez, G., Maya, P. \& Morales, A. (2001). A stable design of PI control for DC-DC converters with an RHS zero, IEEE Transactions on Circuits and Systems I: Fundamental Theory and Applications, 48(1), 103-106.

Beale, M., Hagan, M. \& Demuth, H. (2010). MATLAB: Neural Network Toolbox 7 User's Guide. Natick, MA: The MathWorks.

El-Ghanam, S. M. (2020). Design, implementation and performance analysis of positive super-lift Luoconverter based on different MOSFET types, Indian Journal of Physics, 94(6), 833-839.

Elmas, C., Deperlioglu, O. \& Sayan, H. (2009). Adaptive fuzzy logic controller for DC-DC converters, Expert Systems with Applications, 36(2), 1540-1548.

Garcerá, G., Figueres, E., Pascual, M. \& Benavent, J. M. (2004). Robust model following control of parallel buck converters, IEEE Transactions on Aerospace and Electronic Systems, 40(3), 983-997.

Goudarzian, A. \& Khosravi, A. (2018). Design, analysis, and implementation of an integral terminal reduced-order sliding mode controller for a self-lift positive output Luo converter via Filippov's technique considering the effects of parametric resistances, International Transactions on Electrical Energy Systems, 29(4). DOI: 10.1002/etep.2776

Guo,L.,Hung, J.Y.\&Nelms, R.M.(2011).Comparative evaluation of sliding mode fuzzy controller and PID controller for a boost converter, Electric Power Systems Research, 81(1), 99-106.

Gupta, T., Boudreaux, R. R., Nelms, R. M. \& Hung, J. Y. (1997). Implementation of a fuzzy controller for DC-DC converters using an inexpensive 8-b microcontroller, IEEE transactions on Industrial Electronics, 44(5), 661-669.

Hassan, M. Y. \& Kothapalli, G. (2012). Comparison between neural network based PI and PID controllers. In 2010 7th International Multi-Conference on Systems, Signals and Devices (pp. 1-6).

Leyva, R., Martinez-Salamero, L., Jammes, B., Marpinard, J. C. \& Guinjoan, F. (1997). Identification and control of power converters by means of neural networks, IEEE Transactions on Circuits and Systems I: Fundamental Theory and Applications, 44(8), 735-742.
Lu, D. D., Cheng, D. W. \& Lee, Y. S. (2003). A singleswitch continuous conduction-mode boost converter with reduced reverse-recovery and switching losses, IEEE Transactions on Industrial Electronics, 50(4), 767-776.

Luo, F. L. \& Ye, H. (2003). Positive output superlift converters, IEEE Transactions on Industrial Electronics, 18(1), 105-113.

Nguyen, M. K., Duong, T. D., Lim, Y. C. \& Kim, Y. J. (2018). Isolated boost DC-DC converter with three switches, IEEE Transactions on Power Electronics, 33(2), 1389-1398.

Ofoli, A. R. \& Rubaai, A. (2006). Real-time implementation of a fuzzy logic controller for switch-mode power-stage DC-DC converters, IEEE Transactions on Industry Applications, 42(6), 1367-1374.

Repecho, V., Biel, D., Olm, J. M. \& Fossas, E. (2018). Robust sliding mode control of a DC/DC Boost converter with switching frequency regulation, Journal of the Franklin Institute, 355(13), 5367-5383.

Seshagiri, S. \& Khalil, H. K. (2000). Output feedback control of nonlinear systems using RBF neural networks, IEEE Transactions on Neural Networks, 11(1), 69-79.

Shoja-Majidabad, S. \& Hajizadeh, A. (2020). Decentralized adaptive neural network control of cascaded DC-DC converters with high voltage conversion ratio, Applied Soft Computing, 86, 105878.

Tan, S. C. \& Lai, Y. M. (2008). Constant-frequency reduced-state sliding mode current controller for Cuk converters, IET Power Electronics, 1(4), 466-477.

Tran, V. T., Nguyen, M. K., Choi, Y. O. \& Cho, G. B. (2018). Switched-capacitor-based high boost DC-DC converter, Energies, 11(4), 987.

Venkatesh, V \& Kamalakannan, C. (2016). Real time analysis of positive output super lift converter using ANN controller, Studies in Informatics and Control, 25(3), 323-334. DOI: 10.24846/v25i3y201606

Zhu, M. \& Luo, F. L. (2009). Super-lift DC-DC converters: graphical analysis and modelling, Journal on Power Electronics, 9(6), 854-865. 